\title{
Dermatological Manifestations of Wilson's Disease: Two Cases
}

\section{Rubaiyat Alam ${ }^{1 *}$ \\ A S M Bazlul Karim ${ }^{1}$ \\ Md. Rukunuzzaman ${ }^{1}$ \\ Kamal Hossen ${ }^{1}$ \\ Shashi Bhushan Thakur ${ }^{1}$ \\ Mohammad Moin Uddin²}

${ }^{1}$ Department of Pediatric Gastroenterology and Nutrition Bangabandhu Sheikh Mujib Medical University Dhaka, Bangladesh.

${ }^{2}$ Department of Physical Medicine Chittagong Medical College Chittagong, Bangladesh.

\section{*Correspondence to:}

\section{Dr. Rubaiyat Alam}

Resident

Department of Pediatric Gastroenterology and Nutrition Bangabandhu Sheikh Mujib Medical University Dhaka, Bangladesh.

Mobile : +881732255477

Email:dr.rubaiyat@yahoo.com

\begin{abstract}
Wilson's disease, an autosomal recessive disorder of copper metabolism, most commonly presents either with hepatic or neurological features. But it may sometimes have certain atypical presentations which may lead to diagnostic difficulties. We report here two cases who were diagnosed as Wilson's disease with prominent skin lesions over both lower extremities. These cases are reported here as it is rare and to highlight the fact that early recognition of the skin lesions may play a role in the diagnosis of Wilson's disease. The need to highlight the importance of skin lesion as a pointer to the early diagnosis of Wilson's disease because specific treatment can prevent further liver injury and neurological complications in most cases.
\end{abstract}

Key words: Skin lesions; Wilson's disease; Copper matabolism.

\section{INTRODUCTION}

Wilson's Disease (WD) is an autosomal recessive disorder of copper metabolism caused by mutations in a gene, ATP7B, encoding a copper-transporting, P-type ATPase which leads to progressive copper accumulation in the liver and subsequent deposition in other organs, such as brain, corneas, kidneys, bones, and joints. Though most of the patients present with hepatic and neuro-psychiatric features, they may present with other features like renal tubular acidosis, nephrolithiasis, premature osteoporosis, arthritis, cardiomyopathy, pancreatitis, hypoparathyroidism, and infertility or repeated miscarriages ${ }^{1}$. Dermatological findings are another uncommon presentation. There are only a few case reports/case series describing cutaneous manifestations with Wilson's disease ${ }^{2-5}$. Here we report two cases who were diagnosed as WD with prominent skin lesions over both lower extremities. These cases are reported here as it is rare and to highlight the fact that early recognition of the skin lesions may play a role in the diagnosis of WD.

\section{CASE REPORT- 1}

An 11-year-old girl came to Pediatric Gastroenterology Department of Bangabandhu Sheikh Mujib Medical University, Dhaka, Bangladesh with the complaints of jaundice and skin lesions over both legs for 1 month. She had no history of fever, abdominal pain, blood transfusion, taking any offending drug, bleeding manifestation, convulsionor family history of liver disease or neuropsychiatric involvement but had history of jaundice at 5 years of age. Her parents were firstdegree cousins and she is the only child.

On examination, she was mildly pale, moderately icteric, and had pedal edema. Her vitals were within normal limit, weight $35 \mathrm{~kg}$ and height $147 \mathrm{~cm}$ both lies within centile chart. Kayser- 
Fleischer (KF) ring was present on both eyes. She had hepatomegaly ( $5 \mathrm{~cm}$ palpable below right costal margin) and splenomegaly (6 $\mathrm{cm}$ below left costal margin). Physical examination showed well defined painless, pinkish, dry, itchy and scaly skin lesions and some fine cracks on the skin over extensor surface of both legs (Figure 1). The mucous membranes, palms, soles, hair, nails and teeth were normal.Examinations of other systems were un-remarkable.

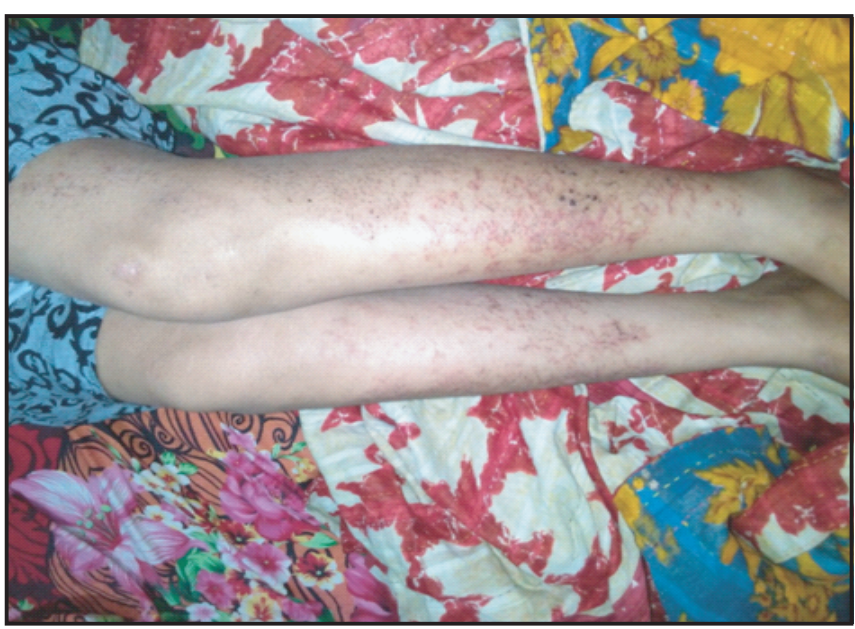

Figure 1: 11 year old girl showing pinkish irritated, dry, itchy and scaly lesions on the skin over extensor surface of both legs.

Investigations findings are listed in table 1.The child was diagnosed as a case of WD and was started copper restricted diet and oral Penicillamine $(20 \mathrm{mg} / \mathrm{kg} /$ day in two divided doses). Dermatological consultation was taken and emollient with antihistamine were given as advised by dermatologist and dramatic improvement of skin manifestations were observed after 5 months of treatment.

Table 1: Investigation details of case 1 and case 2.

\begin{tabular}{lll}
\multicolumn{1}{c}{ Investigations } & \multicolumn{1}{c}{ Case Report 1 } & \multicolumn{1}{c}{ Case Report 2 } \\
Complete blood count & $\mathrm{Hb} \% 9.9 \mathrm{gm} / \mathrm{dl}$ & $\mathrm{Hb} \% 10.1 \mathrm{gm} / \mathrm{dl}$ \\
& Platelet count 140,000/cu mm & Platelet count 80,000/cumm \\
Peripheral blood film & Microcytic hypochromic anaemia & Pancytopenia \\
Serum Total Bilirubin & $6.5 \mathrm{mg} / \mathrm{dl}$ & $2.3 \mathrm{mg} / \mathrm{dl}$ \\
$\mathrm{ALT}$ & $84 \mathrm{U} / \mathrm{L}$ & $57 \mathrm{U} / \mathrm{L}$ \\
INR & 1.81 & 1.77 \\
Serum albumin & $2.3 \mathrm{mg} / \mathrm{dl}$ & $2.4 \mathrm{mg} / \mathrm{dl}$ \\
Serum ceruloplasmin & $7 \mathrm{mg} / \mathrm{dl}$ & $4 \mathrm{mg} / \mathrm{dl}$ \\
Urinary copper before Penicillamine & $180 \mu \mathrm{gm} /$ day & $265 \mu \mathrm{gm} /$ day \\
Urinary copper after Penicillamine & $2360 \mu \mathrm{gm} / \mathrm{day}$ & $1200 \mu \mathrm{gm} /$ day \\
Viral markers & Negative & Negative \\
Ultrasonography of abdomen & Coarse hepatic echotexture & Suggestive of chronic \\
& & liver disease \\
Upper GIT endoscopy & Normal & Grade II esophageal varices \\
Histopathogy of skin & Non specific dermatitis & Non specific dermatitis \\
\hline
\end{tabular}

ALT: Alanine aminotransferase

INR: International normalization ratio.

\section{CASE REPORT-2}

A 12-year-old boy first issue of a consanguineous marriage came to Pediatric Gastroenterology Department of Bangabandhu Sheikh Mujib Medical University, Dhaka with the complaints of jaundice, ascites and blackish lesion over both legs for 1 month. He had no history of taking any offending drug, bleeding manifestation, neurological involvement but had family history of liver disease, three of his cousin brothers died from liver disease.

On examination, there was diffuse and uniform hyper pigmentation all over the body. He had mild pallor, icterus and bilateral pedal edema. His vitals were within normal limit, weight $42 \mathrm{~kg}$ and height $150 \mathrm{~cm}$ both lies within centile chart. Slit lamp examination of eyes showed bilateral K-F rings. He had ascites, hepatomegaly ( $5 \mathrm{~cm}$ below right costal margin) and splenomegaly $(6 \mathrm{~cm})$. The child had peripheral stigmata of chronic liver disease such asleukonychia, gynaecomastia and testicular atrophy. Cutaneous examination showed hypermigmented, itchy, dry, scaly lesion on the skin over extensor surface of both legs and dorsum of feet (Figure 2). The mucous membranes, palms and soles, hair, nails and teeth were normal. Examinations of other systems were within normal limits.

His investigations findings are given in table 1 . The child was diagnosed as a case of Wison's disease as he had bilateral KF rings, low serum ceruloplamin and high urinary copper and he was started on copper restricted diet, d-penicillamine (20 $\mathrm{mg} / \mathrm{kg} /$ day). Dermatological consultation was taken and Clobetasol propionate cream, liquid paraffin and vaseline were given as advised by dermatologist and it showed little improvement of his cutaneous findings even 2 months after starting treatment.

We did a family screening. He had two younger female sibs both were asymptomatic and did not show any abnormality clinically or biochemically.

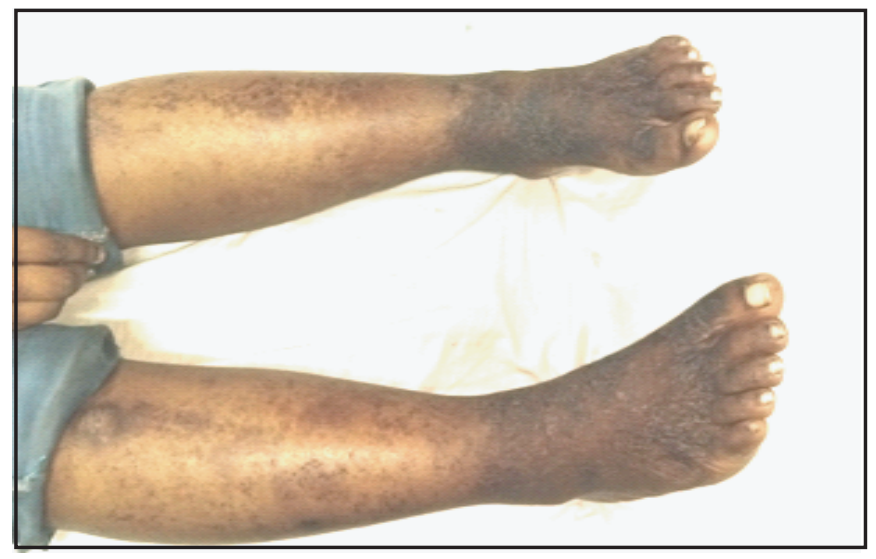

Figure 2 : 12 year old boy showing hyperpigmented, itchy, dry, scaly lesion on the skin over extensor surface. 


\section{DISCUSSION}

Wilson's disease,though classically presents with hepatic, neurological and psychiatric manifestations, can have other uncommon manifestations also. Dermatological changes in WD are very rare and there are only a few published reports (Mainly in the form of case reports). Out of many large series published on Wilson's disease, we could find only one research article in which the authors have reported the incidence of dermatological signs in WD. Seyhan et al in a study of 37 children with WD have shown that $70.3 \%$ had at least one dermatological finding ${ }^{2}$. They also showed that $67.5 \%, 13.5 \%$ and $24.3 \%$ patient had at least one skin, mucosal and nail finding respectively and most common finding was xerosis of skin $(45.7 \%)^{2}$. Xerosis of skin was the clinical diagnosis in both of our cases and was supported by histological finding which was labeled as chronic non-specific dermatitis. Though xerosis is commonly a manifestation of atopic dermatitis, none of our patients full filled major diagnostic criteria of atopic dermatitis $^{6}$. In our cases dermatological findings were not associated with any drug usage, disease severity, malnutrition or duration of disease. Moreover, both of our patients were newly diagnosed WD cases.Gurubacharya et al reported a case of Wilson's disease in a 9-year-old child with generalized hyperpigmentation with liver disease like our second case who had also generalized hyperpigmentation ${ }^{3}$. Steiner et al reported a case in a 16-year-old adolescent who presented with signs of hypersplenism due to cirrhosis and neurological disturbances with hyperpigmentation localized to $\operatorname{legs}^{4}$. Another case report from India described a patient of Wilson's disease in a 9year-old boy with generalized hyperpigmentation with neurological involvement unlike our patients and who had hepatic manifestations only ${ }^{8}$. Though our second case had generalized hyperpigmentation but both of them had marked lesions on extensor surface of legs. In a series of 36 adults with WD,Leu et al found skin hyperpigmentation in 4 cases $(11.1 \%)^{5}$. The most striking finding in WD is the blue lunulae of the nails and it was found in $10 \%$ of patients ${ }^{7-8}$. In addition, there may be gray-brown hyperpigmentation, which develops mostly on the lower extremities ${ }^{7}$. A vague greenish discoloration of the skin on the face, neck and genitalia has also been described ${ }^{8}$. All these dermatological findings, however, have been reported in adult patients. Like our cases the only pediatric study on dermatological manifestation of WD was reported by Seyhan et al but they did not find blue lunulae ${ }^{2}$.

In a study of 20 adults with Wilson's disease from Taiwan, authors reported skin hyperpigmentation in 12 out of 20 cases $(60 \%)$. Histopathological analysis of skin samples showed increased melanin deposits whereas copper and iron content was not different from that in controls ${ }^{9,10}$. Due to lack of facilities we could not measure the iron, copper or melanin content of the skin lesions. As we could not do mutational analysis due to lack of facilities in our country, we are also unable to comment on the genotype-phenotype correlation of hyperpigmentation in Wilson's disease. Future long term studies may be needed.

\section{CONCLUSION}

Diagnosis may be delayed because of wide spectrum of symptoms in patients with WD. Dermatological manifestations, though uncommon, may be the presenting feature of WD. Our cases highlight the importance of looking for other features of WD (Especially liver) in such cases to make an early diagnosis.

\section{DISCLOSURE}

All the authors declared no competing interest. 


\section{REFERENCES}

1. Eve A. Roberts1 and Michael L. Schilsky, Diagnosis and treatment of Wilson disease: An update. Hepatology. 2008;47(6): $2089-2111$.

2. SeyhanM ,Erdem T , Mukadder A. Selimo L and Ertekin V,Dermatological signs in Wilson's disease. Pediatrics International. 2009; 51:395-398.

3. Gurubacharya SM, Gurubacharya RL. Atypical presentation of Wilson's disease. J Nepal Paediatr Soc. 2008; 28:66-67.

4. Steiner P, Frey P, Lupi GA, Kistler HJ. Familial Wilson's disease: Copper indued hemolysis, hypersplenism and hyperpigmentation as the main symptoms. Schweiz Med Wochenschr 1975; 105:872-879.

5. Leu ML, Strickland GT, Wang CC, Chen TS. Skin pigmentation in Wilson's disease. JAMA. 1970;211:1542-1537.

6. Brenninkmeijer E E, Schram M E, Leeflang M M, Bos J D, Spuls P I.Diagnostic criteria for atopic dermatitis: A systematic review. Br. Med. J. 2008; 158(4): 754-765.

7. Braun-Falco O ,Plewing G, Wolf HH, Burgdorf WHC . Disorder of Mineral Metabolism. Dermatology, 2nd edn. Springer, Berlin. 2000.

8. James WD, Berger TG ,Elston D.Errors in Metabolism. Andrews Diseases of the Skin. Clinical Dermatology, 10th edn . Saunders Elsevier, Canada. 2006.

9. Nandi M, Sarkar S, and Mondal R. Generalized hyperpigmentation in Wilson's disease: An unusual association.J Neurosci Rural Pract. 2013 ; 4(1): 70-72.

10. Leu ML, Strickland GT, Wang CC, Chen TS. Skin pigmentation in Wilson's disease. JAMA. 1970;211:1542-1543. 